\title{
Management of benign prostatic hyperplasia with silodosin
}

\author{
This article was published in the following Dove Press journal: \\ Open Access Journal of Urology \\ 19 August 2009 \\ Number of times this article has been viewed
}

\author{
Tomonori Yamanishi' \\ Tomoya Mizuno' \\ Takao Kamai' \\ Ken-Ichiro Yoshida' \\ Ryuji Sakakibara ${ }^{2}$ \\ Tomoyuki Uchiyama ${ }^{3}$ \\ 'Department of Urology, Dokkyo \\ Medical University, Tochigi, Japan; \\ 2Department of Neurology, Sakura \\ Hospital, Toho University, Toho, Japan; \\ ${ }^{3}$ Department of Neurology, Chiba \\ University, Chiba, Japan
}

\begin{abstract}
It has been reported that blockade of $\alpha_{1 \mathrm{~A}}$-adrenoceptor (AR) relieves bladder outlet obstruction, while blockade of $\alpha_{1 \mathrm{D}}$-AR is believed to alleviate storage symptoms due to detrusor overactivity. Silodosin, (-)-1-(3-hydroxypropyl)-5-[(2R)-2-(\{2-[2-(2,2,2trifluoroethoxy) phenoxy] ethyl \}amino)propyl]-2,3-dihydro-1H-indole-7- carboxamide, is a new $\alpha_{1 \mathrm{~A}}$-AR selective antagonist. Silodosin is highly selective for the $\alpha_{1 \mathrm{~A}}$-AR subtype, showing an affinity for the $\alpha_{1 \mathrm{~A}}$-AR that is 583- and 55.5-fold higher than its affinity for the $\alpha_{1 \mathrm{~B}}$ - and $\alpha_{1 \mathrm{D}}$-ARs, respectively. In randomized, double-blind, placebo-controlled phase III studies performed in Japan and the United States, silodosin has been shown to be effective for both storage and voiding symptoms associated with benign prostatic hyperplasia. Early effects of silodosin (after 2-6 hours or day 1) on lower urinary tract symptoms have also been reported. In urodynamic studies, detrusor overactivity disappeared in $40 \%$ and improved in $35 \%$ of patients after administration. In pressure flow studies, the grade of obstruction on the International Continence Society nomogram showed improvement in $56 \%$ of patients. The rate of adverse events in the silodosin, tamsulosin and placebo groups was $88.6 \%, 82.3 \%$, and $71.6 \%$, respectively. The most common adverse event was (mostly mild) abnormal ejaculation (28.1\%). However, few patients $(2.8 \%)$ discontinued silodosin because of abnormal ejaculation. Orthostatic hypotension showed a similar incidence in the silodosin $(2.6 \%)$ and placebo $(1.5 \%)$ groups. In conclusion, silodosin improves detrusor overactivity and obstruction and thus may be effective for both storage and voiding symptoms in patients with benign prostatic hyperplasia.
\end{abstract}

Keywords: alpha-blocker, silodosin, benign prostatic hyperplasia, lower urinary tract symptoms

\section{Introduction}

Benign prostatic hyperplasia $(\mathrm{BPH})$ is a common enlargement of the prostate gland that may lead to bladder outlet obstruction, lower urinary tract symptoms (LUTS), and impaired quality of life. BPH is present in 50\% of men aged over 50 years, and in about $90 \%$ of those over the age of 80 years. ${ }^{1-3}$ BPH is a progressive condition. Investigation of the natural history of $\mathrm{BPH}$ has demonstrated that there is an average annual increase of the International Prostate Symptom Score (IPSS) by 0.18 points, an annual decrease of the maximum flow rate (Qmax) by $2 \%$, and a median increase of prostate volume by $1.9 \%$ annually. ${ }^{4}$

The causes of LUTS associated with BPH (LUTS/BPH) include mechanical compression of the urethra due to enlargement of the prostate (mechanical obstruction), and increased urethral resistance induced by an increment of smooth muscle tone due to increased activity of the sympathetic nerves in the lower urinary tract, including prostatic tissue, posterior urethra and bladder neck (functional obstruction). ${ }^{1}$
Correspondence: Tomonori Yamanishi Department of Urology, Dokkyo Medical University, 880 Kitakobayashi, Mibu,

Tochigi, 32I-0293, Japan

$\mathrm{Tel}+8 \mathrm{I} 28286 \mathrm{IIII}$

Fax +8I 282867533

Email yamanish@dokkyomed.ac.jp
Open Access Journal of Urology 2009: I I-7

(C) 2009 Yamanishi et al, publisher and licensee Dove Medical Press Ltd. This is an Open Access article which permits unrestricted noncommercial use, provided the original work is properly cited. 
Because baseline tone is present in prostate smooth muscle (due to its rich sympathetic innervation), blockade of prostatic $\alpha_{1}$-adrenoceptor (AR) results in prostate smooth muscle relaxation, and thus alleviates the dynamic component of BPH. ${ }^{1}$

There are various options for the treatment of $\mathrm{BPH}$, including transurethral resection of the prostate, ${ }^{5,6}$ minimally invasive therapies for $\mathrm{BPH}$ including microwave thermotherapy, ${ }^{7}$ holmium:YAG laser prostatectomy, ${ }^{8,9}$ or transurethral resection in saline (TURIS), ${ }^{10,11}$ and pharmacotherapy. Among these options, medical therapy with an $\alpha_{1}$-AR antagonist is widely used as a conservative treatment for LUTS/BPH or neurogenic bladder dysfunction. ${ }^{12-17}$ It has been reported that $\alpha_{1}$-AR antagonists are effective for both storage and voiding symptoms by decreasing bladder outlet obstruction and alleviating detrusor overactivity. ${ }^{14,18-20}$

The adrenergic receptors were originally divided into $\alpha$-AR and $\beta$-AR categories, but application of molecular biological methods has since confirmed nine total AR subtypes: $\alpha_{1 \mathrm{a}}, \alpha_{1 \mathrm{~b}}, \alpha_{1 \mathrm{~d}}, \alpha_{2 \mathrm{a}}, \alpha_{2 \mathrm{~b}}, \alpha_{2 \mathrm{c}}, \beta_{1}, \beta_{2}$, and $\beta_{3}{ }^{1,21,22}$

It was reported that the $\alpha_{1 \mathrm{~A}}$-AR subtype is predominant in the prostate, ${ }^{23}$ but recent studies have detected the expression of both $\alpha_{1 \mathrm{~A}}$ - and $\alpha_{1 \mathrm{D}}$-ARs in human prostate tissue. ${ }^{24-26}$ It has been reported that $\alpha_{1 \mathrm{~A}}$-AR blockade relieves bladder outlet obstruction, while the blocking the $\alpha_{1 D}$-AR is believed to alleviate storage symptoms due to detrusor overactivity. ${ }^{1}$ However, silodosin (KMD-3213 or [(-)-1-(3-hydroxypropyl)5-[(2R)-2-(\{2-[2-(2,2,2trifluoroethoxy)phenoxy] ethyl\}amino) propyl]-2,3-dihydro-1H-indole-7-carboxamide]), a new $\alpha_{1 A^{-}}$ AR selective antagonist, has been reported to be effective for both storage and voiding symptoms in BPH patients. ${ }^{27,28}$ This suggests that the $\alpha_{1 \mathrm{~A}}-\mathrm{AR}$ alone is responsible for both storage and voiding symptoms in LUTS/BPH.

This review discusses the efficacy of silodosin for the treatment of LUTS/BPH, as well as the role of the $\alpha_{1 \mathrm{~A}}-\mathrm{AR}$ for storage and voiding dysfunction in $\mathrm{BPH}$.

\section{Pharmacology, mode of action, and pharmacokinetics of silodosin}

Silodosin is highly selective for the $\alpha_{1 \mathrm{~A}}$-AR subtype, showing an affinity for the $\alpha_{1 \mathrm{~A}}$-AR that is 583- and 55.5-fold higher than its affinity for the $\alpha_{1 \mathrm{~B}}-$ and $\alpha_{1 \mathrm{D}}-\mathrm{ARs}$, respectively (Table 1). ${ }^{29,30}$ The selectivity of silodosin for the $\alpha_{1 \mathrm{~A}}-\mathrm{AR}$ versus the $\alpha_{1 \mathrm{~B}}$-AR was reported to be 38 -fold greater than that of tamsulosin hydrochloride in studies using Chinese hamster ovary cells expressing three human $\alpha_{1}$-AR subtypes. ${ }^{27,29}$ Evaluation of the uroselectivity of silodosin and comparison with that of tamsulosin and prazosin in vivo has shown that silodosin demonstrates good uroselectivity (determined from the ratio of the dose reducing intraurethral pressure to that decreasing blood pressure), in rats and dogs. ${ }^{31,32}$

Murata and colleagues ${ }^{33}$ performed binding experiments with $\left[{ }^{3} \mathrm{H}\right]-\mathrm{KMD}$ (silodosin) and $\left[{ }^{3} \mathrm{H}\right]$-prazosin using human prostatic or aortic membranes and found that $\left[{ }^{3} \mathrm{H}\right]-\mathrm{KMD}$ bound to prostatic membranes with a higher affinity than $\left[{ }^{3} \mathrm{H}\right]$-prazosin, but did not bind strongly to aortic membranes. Investigation of competition with $\left[{ }^{3} \mathrm{H}\right]$-prazosin revealed that silodosin had over 200-fold higher affinity for human prostatic membranes than for aortic membranes. In functional experiments, silodosin exhibited more than 100-fold higher affinity for human prostate tissue than for the mesenteric artery. By measuring the specific binding of $\left[{ }^{3} \mathrm{H}\right]$ prazosin to the rat prostate after oral administration of silodosin, Yamada and colleagues ${ }^{34}$ estimated that $\alpha_{1}$-AR occupancy in the human prostate would be around $60 \%-70 \%$ at $1-6$ hours after the oral administration of silodosin at doses of 3.0, 8.1, and $16.1 \mu \mathrm{mol}$. Thereafter, receptor occupancy decreased to $24 \%(8.1 \mu \mathrm{mol})$ and $54 \%(16.1 \mu \mathrm{mol})$ by 24 hours. Despite there being almost two orders of difference in the free plasma concentration achieved by clinically effective oral dosages of silodosin, tamsulosin, and terazosin, there is comparable prostatic $\alpha_{1}$-AR occupancy by these drugs.

\section{Efficacy of silodosin in the treatment of BPH}

In Japan, $8 \mathrm{mg} /$ day (4 mg twice daily) was considered to be the recommended clinical dose of silodosin, based on the results of phase II and phase III trials of $4 \mathrm{mg} /$ day versus $8 \mathrm{mg} /$ day in patients with LUTS/BPH. ${ }^{27}$ In the United States, a dosage of $8 \mathrm{mg}$ once daily was used in phase III studies. $^{28}$

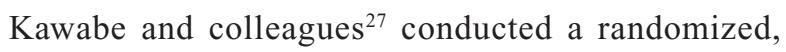
double-blind, placebo-controlled study of silodosin for $\mathrm{BPH}$ at 88 centers in Japan. Inclusion criteria were men aged $\geq 50$ years with an IPSS of $\geq 8$, a quality-of-life (QoL)

Table I Affinity $(\mathrm{Ki})$ values of silodosin and other $\alpha_{1}$-AR antagonists at cloned human $\alpha_{1}$-adrenoceptors

\begin{tabular}{lllllll}
\hline & \multicolumn{4}{l}{ Ki (nM) $\alpha_{1}$-AR subtype selectivity } & \\
\cline { 2 - 5 } & $\alpha_{\text {IA }}$-AR & $\alpha_{\text {IB }}$-AR & $\alpha_{\text {ID }}$-AR & $\alpha_{\text {IA }}$ vs $\alpha_{\text {IB }}$ & $\alpha_{\text {IA }}$ vs $\alpha_{\text {ID }}$ \\
\hline Silodosin $^{29}$ & 0.036 & 21.0 & 2.0 & 583.3 & 55.5 \\
Tamsulosin $^{30}$ & 0.019 & 0.29 & 0.063 & 15.2 & 3.32 \\
Naftopidil $^{30}$ & 3.7 & 20.1 & 1.2 & 5.4 & 0.32 \\
Prazosin $^{30}$ & 0.17 & 0.25 & 0.066 & I.47 & 0.39 \\
\hline
\end{tabular}


score $\geq 3$, a Qmax $<15 \mathrm{~mL} / \mathrm{s}$, a prostate volume of $\geq 20 \mathrm{~mL}$ and a postvoid residual urine volume of $<100 \mathrm{~mL}$. A total of 457 patients were randomized to receive silodosin at $4 \mathrm{mg}$ twice daily $(\mathrm{n}=176)$, tamsulosin at $0.2 \mathrm{mg}$ once daily $(n=192)$, or placebo $(n=89)$ for 12 weeks. The change of the total IPSS from baseline (primary endpoint) was $-8.3,-6.8$, and -5.3 in the silodosin, tamsulosin, and placebo groups, respectively. There was a significant decrease of the IPSS in the silodosin group from one week compared with the placebo group. In the early comparison, silodosin therapy achieved a significant decrease of the IPSS after two weeks compared with tamsulosin therapy. The change of QoL from baseline was $-1.7,-1.4$, and -1.1 in the silodosin, tamsulosin, and placebo groups, respectively, and silodosin achieved a significant improvement of the QoL score relative to placebo. In the subgroup of patients with severe symptoms (IPSS $\geq 20$ ) silodosin also achieved significantly better improvement than placebo ( $-12.4 \mathrm{vs}-8.7)$. Therefore, silodosin improved both storage and voiding symptoms in patients with LUTS/BPH. The response to silodosin persisted for 52 months in the long-term extension study. ${ }^{35}$

Marks and colleagues ${ }^{28}$ assessed the efficacy and safety of silodosin for the treatment of BPH in two randomized, placebo-controlled, phase III studies. Of 923 patients with a mean age of 65 years, 466 received silodosin ( $8 \mathrm{mg} /$ day) and 457 were given placebo with breakfast for 12 weeks. After 0.5 weeks (three to four days) of treatment, patients receiving silodosin showed significant improvement in total IPSS (difference $-1.9, \mathrm{p}<0.0001)$ and irritative $(-0.5, \mathrm{p}=0.0002)$ and obstructive $(-1.4, \mathrm{p}<0.0001)$ subscores compared with the placebo group. The mean change from baseline in total IPSS was -4.2 for silodosin vs -2.3 for placebo, and between differences in IPSS and subscores increased by week 12 $(\mathrm{p}<0.0001)$. Mean change from baseline in $\mathrm{Qmax}(\mathrm{ml} / \mathrm{s})$ two to six hours after initial dose was greater $(\mathrm{p}<0.0001)$ with silodosin $(2.8 \pm 3.4)$ than placebo $(1.5 \pm 3.8)$. Differences remained significant $(p<0.001)$ through week 12 .

Takao and colleagues ${ }^{36}$ evaluated the early efficacy of silodosin for treatment of 68 patients with LUTS/BPH. Total IPSS and QoL index improved significantly from $19.38 \pm 7.46$ and $4.68 \pm 1.07$ at baseline to $15.81 \pm 7.40$ and $4.22 \pm 1.30$ at day 1 , respectively. The subscores of voiding, storage, and post-micturition symptoms showed a significant decrease from $8.93 \pm 3.95,7.97 \pm 3.88$, and $2.49 \pm 1.70$ at baseline to $7.28 \pm 4.09,6.52 \pm 3.47$, and $2.02 \pm 1.56$ at day 1 , respectively. The authors concluded that silodosin improved LUTS and QoL rapidly (from day 1). Ogawa and colleagues ${ }^{37}$ reported similar early effectiveness of silodosin for both storage and voiding symptoms in 187 patients with LUTS/BPH.

\section{Urodynamic effects of silodosin in patients with LUTS/BPH}

We have evaluated urodynamic effects of silodosin in patients with LUTS/BPH. ${ }^{38}$ The mean total IPSS, the mean storage and voiding IPSS subscores, and QOL score decreased significantly after one to 12 months of therapy. In our study with silodosin, Qmax increased significantly from $6.7 \pm 3.0 \mathrm{ml} / \mathrm{sec}$ at baseline to $9.5 \pm 5.0 \mathrm{ml} / \mathrm{sec}, 8.4 \pm 3.5 \mathrm{ml} / \mathrm{sec}, 10.4 \pm 4.5 \mathrm{ml} / \mathrm{sec}$, and $10.5 \pm 5.4 \mathrm{ml} / \mathrm{sec}$ at $1,3,6$, and 12 months of therapy (all $\mathrm{p}<0.05)$. In an urodynamic study $(\mathrm{n}=29)$, maximum cystometric capacity increased significantly $(\mathrm{p}=0.0027)$, and detrusor overactivity disappeared in eight of 20 patients $(40 \%)$ and improved (bladder capacity increased more than 50\%) in seven patients (35\%) after the therapy. In pressure/flow studies $(\mathrm{n}=27)$, the obstruction grade was improved in 15 patients (56\%). Detrusor opening pressure, detrusor pressure at Qmax, bladder outlet obstruction index, and Schäfer's obstruction class decreased significantly after therapy $(\mathrm{p}=0.0010$, $\mathrm{p}<0.0001, \mathrm{p}<0.0001$, and $\mathrm{p}<0.0001$, respectively). Because silodosin appears to improve both detrusor overactivity and obstruction grade, it may be effective for both storage and voiding dysfunction in patients with LUTS/BPH. Matsukawa and colleagues ${ }^{39}$ also performed urodynamic studies in 65 patients with BPH and reported an disappearance of detrusor overactivity in 14 of 21 patients (67\%), and a significant decrease of detrusor pressure at Qmax from 73.9 to $52.4 \mathrm{cmH}_{2} \mathrm{O}(\mathrm{p}<0.001)$ after administration of silodosin $4 \mathrm{mg}$ twice daily for four weeks.

In an animal study, Tatemichi and colleagues ${ }^{40}$ performed cystometry in a hormone-treated rat model of BPH and showed that detrusor overactivity only occurred in male rats, and that silodosin decreased this detrusor overactivity.

\section{Role of $\alpha_{I A}$-adrenoceptor subtype in LUTS/BPH}

Smooth muscle tone in the bladder neck and prostate is mainly regulated by the $\alpha_{1 \mathrm{~A}}$-AR. ${ }^{41,42}$ Thus blockade of $\alpha_{1 \mathrm{~A}}$-AR can lead to smooth muscle relaxation in these areas, resulting in improved symptoms and urinary flow rates. On the other hand, $\alpha_{1 \mathrm{~B}}$-ARs are largely located on vascular smooth muscle, so antagonizing these receptors can cause relaxation of this tissue, and thus impair the cardiovascular mechanisms involved in the regulation of blood pressure. ${ }^{43} \alpha_{1}$-AR expression increases by two-fold in representative (mammary) arteries with aging, with 
the ratio of $\alpha_{1 \mathrm{~b}} / \alpha_{1 \mathrm{a}}$ increasing, whereas no alteration occurs in veins. ${ }^{44}$ A previous meta-analysis showed that the effects of nonselective $\alpha_{1}$-AR antagonists (terazosin or doxazosin), and those of the $\alpha_{1 \mathrm{~A}} / \alpha_{1 \mathrm{D}}-\mathrm{AR}$ antagonist (tamsulosin) were similar, although there was a difference with respect to cardiovascular side effects. ${ }^{1,18}$ Therefore, agents with a high selectivity for the $\alpha_{1 \mathrm{~A}} / \alpha_{1 \mathrm{D}}-\mathrm{AR}$ or $\alpha_{1 \mathrm{~A}}$-AR may have beneficial effects on LUTS/BPH with minimal effects on blood pressure, as occurs with nonselective $\alpha_{1}$-AR antagonists.

It has been reported that blockade of $\alpha_{1 \mathrm{~A}}-\mathrm{AR}$ relieves bladder outlet obstruction, while blockade of $\alpha_{1 D}-A R$ alleviates storage symptoms due to detrusor overactivity. ${ }^{1}$ The role of $\alpha_{1 \mathrm{D}}-\mathrm{AR}$ in detrusor overactivity can be explained as follows. Predominance of $\alpha_{1 D}$-AR over $\alpha_{1 \mathrm{~A}}$-ARs at the mRNA and protein levels has been reported in human detrusor. ${ }^{45}$ An increase in $\alpha_{1 \mathrm{D}}$-AR mRNA and protein expression was reported in obstructed and hypertrophied rat bladder, suggesting a possible role of $\alpha_{1 D}-A R$ in controlling detrusor overactivity. ${ }^{46}$ However, the expression of $\alpha_{1}$-ARs has been reported to be too low to produce contraction in normal and obstructed human bladders. ${ }^{47}$ Another possible mechanism by which $\alpha_{1}$-AR antagonists could alleviate detrusor overactivity may be inhibition of the micturition reflex by acting on $\alpha_{1 \mathrm{D}}$-ARs in the lumbosacral spinal cord. ${ }^{48,49}$ Although the expression of $\alpha_{1 \mathrm{D}}$-ARs seems to be predominant in the human spinal cord, ${ }^{48}$ intrathecal injection of $\alpha_{1 D}$ - or $\alpha_{1 \mathrm{~A}}$-AR selective antagonists inhibits the micturition reflex in the rat. ${ }^{49,50}$ Moreover, it has not been confirmed whether the commercially available $\alpha_{1}$-AR antagonists are distributed to the spinal cord. Consequently, it is unclear whether the $\alpha_{1 D}-A R$ is the only AR subtype responsible for detrusor overactivity.

It has been reported that nocturia responds to $\alpha_{1 D}-A R$ blockade. In a cross-over study comparing tamsulosin $\left(\alpha_{1 \mathrm{~A}}-\mathrm{AR}>\alpha_{1 \mathrm{D}}-\mathrm{AR}\right)$ with naftopidil $\left(\alpha_{1 \mathrm{D}}-\mathrm{AR}>\alpha_{1 \mathrm{~A}}-\mathrm{AR}\right)$, relief of storage symptoms was significantly better in subjects given naftopidil. ${ }^{1,51-54}$ However, this issue is still controversial and different results have been reported by other authors. ${ }^{1,55,56}$ Recently, Kira and colleagues ${ }^{57}$ studied the efficacy of silodosin in 85 patients with LUTS/BPH who were resistant to tamsulosin $(n=39)$ or naftopidil $(n=46)$, and reported a rapid and significant decrease in scores of decreased urinary stream and nocturia (both $\mathrm{p}<0.01$ ), which were the most bothersome symptoms among IPSS. All of the clinically available $\alpha_{1}$-AR antagonists have $\alpha_{1 \mathrm{~A}}$-AR antagonist activity to a greater or lesser extent, so the effect of these drugs on storage symptoms and nocturia may not be solely related to blockade of the $\alpha_{1 D}-$ AR.
We previously performed urodynamic studies of naftopidil, an $\alpha_{1 \mathrm{~A}} / \alpha_{1 \mathrm{D}}$ - adrenoceptor selective antagonist, and found that detrusor overactivity disappeared in three (21\%) and improved in five (36\%) of 14 patients with detrusor overactivity. ${ }^{20}$ Consequently, the effects of silodosin on detrusor overactivity appeared similar to those of naftopidil. ${ }^{20,38}$ Since the affinity of silodosin for the $\alpha_{1 \mathrm{~A}}$-AR is 583- and 55.5-fold higher than its affinity for the $\alpha_{1 \mathrm{~B}}$ - and 1ARs, respectively, ${ }^{29}$ most of the effect of this drug at the clinical doses should be due to $\alpha_{1 \mathrm{~A}}-\mathrm{AR}$ blockade, suggesting that $\alpha_{1 \mathrm{~A}}$-AR is the predominant subtype involved in detrusor overactivity in BPH. One of the reasons that $\alpha_{1 \mathrm{~A}}$-AR antagonists improve both storage and voiding dysfunction may be that bladder outlet obstruction is reduced and this alleviates detrusor overactivity that was caused by obstruction. Improvement in detrusor overactivity may reflect secondary effects due to a relief of prostatic urethral tension. ${ }^{40}$ Another possible mechanism for the improvement of detrusor overactivity is that obstruction causes ischemia (and reperfusion) that leads to detrusor overactivity and bladder dysfunction. ${ }^{58-60}$ The $\alpha_{1 \mathrm{~A}}$-AR may predominate in the small arteries, including the bladder arteries of elderly patients and $\alpha_{1 \mathrm{~A}}$-AR antagonist may therefore increase blood flow to the bladder and thus alleviate detrusor overactivity. ${ }^{43,44}$

Previously, the efficacy of selective $\alpha_{1 \mathrm{~A}}$-AR antagonist has been questioned because RS-17053, N-[2(2-cyclopropylmetho xyphenoxy)ethyl]-5-chloro-alpha,alpha-dimethyl1H-indole3-ethanamine hydrochloride, a selective $\alpha_{1 \mathrm{~A}}$-AR antagonist, effectively relaxed prostate smooth muscle and increased urine flow in men, but did not relieve LUTS. ${ }^{1}$ The difference of efficacy between silodosin and RS-17053 may be due to the difference in their affinity for the $\alpha_{1 L}$-AR. Drugs such as prazosin, RS-17053 and 5-methylurapidil show low affinity for the $\alpha_{1 \mathrm{~L}}-\mathrm{AR}$, but silodosin and tamsulosin show high affinity. The $\alpha_{1 \mathrm{~L}}-\mathrm{AR}$ has pharmacological properties that distinguish it from the three classical $\alpha_{1}-\operatorname{ARs}\left(\alpha_{1 \mathrm{~A}^{-}}, \alpha_{1 \mathrm{~B}}{ }^{-}\right.$, and $\alpha_{1 \mathrm{D}}$-AR). ${ }^{61,62}$ Muramatsu and colleagues ${ }^{61}$ studied radioligand binding and functional bioassay experiments on the cerebral cortex, vas deferens and prostate of wild-type (WT) mice and $\alpha_{1 \mathrm{~A}}-\mathrm{AR}, \alpha_{1 \mathrm{~B}}-\mathrm{AR}$ and $\alpha_{1 \mathrm{D}}-\mathrm{AR}$ gene knockout (AKO, BKO and DKO) mice. They found that $\left[{ }^{3} \mathrm{H}\right]$-silodosin bound to intact segments of the cerebral cortex, vas deferens, and prostate from WT, BKO, and DKO mice, but not AKO mice. The binding sites were composed of two components with high and low affinities for prazosin or RS-17053, indicating the pharmacological profiles of $\alpha_{1 \mathrm{~A}}-\mathrm{AR}$ and $\alpha_{1 \mathrm{~L}}$-AR. In membrane preparations of WT mouse cortex, $\left[{ }^{3} \mathrm{H}\right]$-silodosin bound to a single population of prazosin high-affinity sites, 
suggesting the presence of $\alpha_{1 \mathrm{~A}}$-ARs alone. In contrast, $\left[{ }^{3} \mathrm{H}\right]$-prazosin bound to two components having $\alpha_{1 \mathrm{~A}}-\mathrm{AR}$ and $\alpha_{1 \mathrm{~B}}-\mathrm{AR}$ profiles in intact segments of WT and DKO mouse cortices, but AKO mice lacked $\alpha_{1 \mathrm{~A}}$-AR profiles and BKO mice lacked $\alpha_{1 \mathrm{~B}}$-AR profiles. Noradrenaline produces contraction through $\alpha_{1 \mathrm{~L}}$-ARs in the vas deferens and prostate of WT, BKO and DKO mice. However, such contraction is abolished or markedly attenuated in AKO mice. The $\alpha_{1 \mathrm{~L}}$-AR has been identified as binding and functional entities in WT, BKO, and DKO mice, but not in AKO mice, suggesting that $\alpha_{1 \mathrm{~L}}-\mathrm{AR}$ is one phenotype derived from the $\alpha_{1 \mathrm{~A}}-\mathrm{AR}$ gene. Morishima and colleagues ${ }^{62}$ performed in binding assays with tissue segments and membrane preparations of human prostates using $\left[{ }^{3} \mathrm{H}\right]$-silodosin, and reported that the $\left[{ }^{3} \mathrm{H}\right]$-silodosin binding sites in intact segments were divided into two distinct types with different affinities for prazosin and RS-17053, while the binding sites in membrane preparations showed single high affinity for these drugs. They concluded that the $\alpha_{1 \mathrm{~L}}-\mathrm{AR}$ and $\alpha_{1 \mathrm{~A}}$-AR coexist as pharmacologically distinct entities in intact tissues, but not in crude membrane preparations. In functional experiments, silodosin and tamsulosin potently inhibited the contractile response to noradrenaline, while prazosin, RS-17053 and BMY 7378 showed weak antagonism, suggesting that the $\alpha_{1 \mathrm{~A}}$-AR involved in the contractile response to noradrenaline is the $\alpha_{1 \mathrm{~L}}$-AR subtype.

\section{Safety and tolerability of silodosin}

In a randomized, double-blind, placebo-controlled study reported by Kawabe and colleagues, ${ }^{27}$ the rates of adverse events and drug-related adverse events in the silodosin, tamsulosin, and placebo groups were $88.6 \%, 82.3 \%$, and $71.6 \%$, respectively, and $69.7 \%, 47.4 \%$, and $36.4 \%$, respectively. The most common adverse event in the silodosin group was abnormal ejaculation, which occurred more often in this group than in the tamsulosin group (22.3\% vs $1.6 \%)$.

In two randomized, placebo controlled, phase III studies of silodosin performed in the United States, the most common treatment-emergent adverse event was (mostly mild) retrograde (abnormal) ejaculation ( $28.1 \%$ for silodosin versus $0.9 \%$ for placebo), followed by dizziness $(3.2 \%)$, diarrhea (2.6\%), orthostatic hypotension $(2.6 \%)$ headache $(2.4 \%)$, nasopharyngitis, $(2.4 \%)$, and nasal congestion (2.1\%). However, few patients receiving silodosin $(2.8 \%)$ discontinued because of retrograde ejaculation. Proportions of patients with treatment-emergent orthostatic hypotension were similar for silodosin (2.6\%) and placebo (1.5\%). ${ }^{28}$ It has been reported that tamsulosin can also cause abnormal ejaculation.
The cause of abnormal ejaculation has been reported to be due to decrease of emission caused by decreasing $\alpha_{1 \mathrm{~A}}$-mediated seminal vesicle contraction, or an impaired function of the vas deferens, rather than producing true retrograde ejaculation. ${ }^{1,60,63-65}$ Sanbe and colleagues ${ }^{65}$ reported that contractile tension of the vas deferens in response to noradrenaline was markedly decreased in $\alpha_{1 \mathrm{~A}}$-AR knockout mice, and this contraction was completely abolished in $\alpha_{1}$-AR tripleknockout mice.

Intraoperative floppy iris syndrome (IFIS) is characterized by small pupils and iris billowing during cataract surgery in patients taking $\alpha_{1}$-AR antagonists. ${ }^{1,66}$ The overall prevalence of IFIS is $1 \%-2 \%$ among patients undergoing cataract surgery, but it occurs in $43 \%-63 \%$ of patients taking tamsulosin. ${ }^{67,68}$ However, all $\alpha_{1}$-AR antagonists are capable of producing these effects by blockade of $\alpha_{1 \mathrm{~A}}$-ARs in the iris dilator muscle, and IFIS may occur at a high incidence during silodosin administration. All of the effects of $\alpha_{1}-A R$ antagonists on pupil size resolved within eight hours of administration in the white albino rabbit model. ${ }^{69}$ Iris hooks are required to dilate the pupil when IFIS occurs, so patients planning cataract surgery should inform their ophthalmologist that they are taking $\alpha_{1}-\mathrm{AR}$ antagonists.

\section{Conclusions}

Silodosin improves detrusor overactivity and reduces the grade of obstruction, and thus may be effective for both storage and voiding dysfunction for the treatment of LUTS/BPH. Incidence of orthostatic hypotension was low, and the most common adverse event was mild abnormal ejaculation and thus could be a first-line treatment of LUTS/BPH.

\section{Disclosures}

The authors report no conflicts of interest in this work.

\section{References}

1. Schwinn DA, Roehrborn CG. $\alpha_{1}$-Adrenoceptor subtypes and lower urinary tract symptoms. Int J Urol. 2008;15:139-193.

2. Speakman MJ. Lower urinary tract symptoms suggestive of benign prostatic hyperplasia (LUTS/BPH): more than treating symptoms? Eur Urol Suppl. 2008;7:680-689.

3. Berry SJ, Coffey DS, Walsh PC, Ewing LJ. The development of human benign prostatic hyperplasia with age. J Urol. 1984;132:474-479.

4. Roehrborn CG. BPH progression: concept and key learning from MTOMS, Altess, Combat and Alf-one. BJU Int. 2008;101(Suppl 3): 17-21.

5. MacDonagh RP, Cliff AM, Speakman MJ, et al. The use of generic measures of health-related quality of life in the assessment of outcome from transurethral resection of the prostate. BJU Int. 1997;79:401-408.

6. Rassweiler J, Teber D, Kuntz R, et al. Complications of transurethral resection of the prostate (TUR-P)- incidence, management and prevention. Eur Urol. 2006;50:969-980. 
7. Brehmer M, Nilsson BY. Elevation of sensory thresholds in the prostatic urethra after microwave thermotherapy. BJU Int. 2000;86:427-431.

8. Yamanishi T, Takei K, Tobe T, Ueda T, Ito H, Yasuda K. Transurethral holmium: YAG laser prostatectomy using a side-firing fiber for bladder outlet obstruction due to benign prostatic enlargement: urodynamic evaluation of surgical outcome. Eur Urol. 2001;39:544-550.

9. Seki N, Naito S. Holmium laser for benign prostatic hyperplasia. Curr Opin Urol. 2008;18:41-45.

10. Ho HS, Yip SK, Lim KB, et al. A prospective randomized study comparing monopolar and bipolar transurethral resection of prostate using transurethral resection in saline (TURIS) system. Eur Urol. 2007;52:517-522.

11. Michielsen DP, Debacker T, De Boe V, et al. Bipolar transurethral resection in saline - an alternative surgical treatment for bladder outlet obstruction? J Urol. 2007;178:2035-2039.

12. Arnold EP. Tamsulosin in men with confirmed bladder outlet obstruction: a clinical and urodynamic analysis from a single center in New Zealand. BJU Int. 2001;87:24-31.

13. Yamanishi T, Yasuda K, Sakakibara R, Hattori T, Tojo M. Effectiveness of terazosin, an alpha1-blocker, on bladder neck obstruction as assessed by urodynamic hydraulic energy. BJU Int. 2000;85:249-253.

14. Yasuda K, Yamanishi T, Tojo M, Nagashima K, Akimoto S, Shimazaki J. Effect of naftopidil on urethral obstruction in benign prostatic hyperplasia: assessment by urodynamic studies. Prostate. 1994;25:46-52.

15. Yasuda K, Yamanishi T, Kawabe K, Oshima H, Morita T. The effect of urapidil on neurogenic bladder: a placebo controlled double-blind study. J Urol. 1996;156:1125-1130.

16. Schulman CC, Lock TMTW, Buzelin JM, Boeminghaus F, Stephenson TP, Talja M. Long-term use of tamsulosin to treat lower urinary symptoms/benign prostatic hyperplasia. J Urol. 2001;166:1358-1363.

17. Yamanishi T, Tatssumiya K, Furuya N, et al. Long-term efficacy of tamsulosin in the treatment of lower urinary tract symptoms suggestive of benign prostatic hyperplasia in real-life practice. UroToday Int $J$. 2009;2(1). DOI:10.3834/uij.1944-5784.2009.02.01

18. Djavan B, Marberger M. Meta-analysis on the efficacy and tolerability of $\alpha 1$-adrenoceptor antagonists in patients with lower urinary tract symptoms suggestive of benign prostatic obstruction. Eur Urol. 1999;36:1-3.

19. Djavan B, Chapple C, Marberger M, et al. State of the art on the efficacy and tolerability of alpha-adrenoceptor antagonists in patients with lower urinary tract symptoms suggestive of benign prostatic hyperplasia. Urology. 2004;64:1081-1088.

20. Yamanishi T, Yasuda K, Kamai T, et al. Single-blind, randomized controlled study of the clinical and urodynamic effects of an alphablocker (naftopidil) and phytotherapy (eviprostat) in the treatment of benign prostatic hyperplasia. Int J Urol. 2004;11:501-509.

21. Hawrylyshyn KA, Michelotti GA, Coge F, Guenin SP, Schwinn DA. Update on human alpha1-adrenoceptor subtype signaling and genomic organization. Trends Pharmacol Sci. 2004;25:449-455.

22. Langer SZ. History and nomenclature of $\alpha_{1}$-adrenoceptors. Eur Urol. 1999;36(Suppl):2-6.

23. Price DT, Schwinn DA, Lomasney JW, Allen LF, Caron MG, Lefkowitz RJ. Identification, quantification, and localization of mRNA for three distinct alphaA1 adrenergic receptor subtypes in human prostate. J Urol. 1993;150:546-551.

24. Kojima Y, Sasaki S, Shinoura H, Hayashi Y, Tsujimoto G, Kohri K. Quantification of alpha1-adrenoceptor subtypes by real-time RT-PCR and correlation with age and prostate volume in benign prostatic hyperplasia patients. Prostate. 2006;66:761-767.

25. Kojima Y, Sasaki S, Shinoura H, et al. Change of expression levels of alpha1-adrenoceptor subtypes by administration of alpha1dadrenoceptor-subtype-selective antagonist naftopidil in benign prostate hyperplasia patients. Prostate. 2007;67:1285-1292.

26. Kojima Y, Sasaki S, Kubota Y, et al. Expression of alpha1-adrenoceptor subtypemRNA as a predictor of the efficacy of subtype selective alpha1-adrenoceptor antagonists in the management of benign prostatic hyperplasia. J Urol. 2008;179:1040-1046.
27. Kawabe K, Yoshida M, Homma Y, for the Silodosin Clinical Study Group. Silodosin, a new alpha1A-adrenoceptor-selective antagonist for treating benign prostatic hyperplasia: results of a phase III randomized, placebo-controlled, double-blind study in Japanese men. BJU Int. 2006;98:1019-1024.

28. Marks LS, Gittelman MC, Hill LA, Volinn W, Hoel G. Rapid efficacy of the highly selective alpha1A-adrenoceptor antagonist silodosin in men with signs and symptoms of benign prostatic hyperplasia: pooled results of 2 phase 3 studies. $J$ Urol. 2009;181(6):2634-2640.

29. Shibata K, Foglar R, Horie K, et al. KMD-3213, a novel, potent, $\alpha_{1 \mathrm{~A}}$-adrenoceptor-selective antagonist: characterization using recombinant human $\alpha_{1}$-adrenoceptors and native tissues. Mol Pharmacol. 1995;48:250-258.

30. Takei R, Ikegaki I, Shibata K, Tsujimoto G, Asano T. Naftopidil, a novel $\alpha_{1}$-adrenoceptor antagonist, displays selective inhibition of canine prostatic pressure and high affinity binding to cloned human $\alpha_{1}$-adrenoceptors. Jpn J Pharmacol. 1999;79:447-454.

31. Akiyama K, Hora M, Tatemichi S, et al. KMD-3213, a uroselective and longacting $\alpha 1 \mathrm{~A}$-adrenoceptor antagonist, tested in a novel rat model. J Pharmacol Exp Ther. 1999;291:81-91.

32. Akiyama K, Noto H, Nishizawa O, et al. Effect of KMD-3213, an $\alpha 1 \mathrm{~A}-$ adrenoceptor antagonist, on the prostatic urethral pressure and blood pressure in male decerebrate dogs. Int J Urol. 2001;8:177-183.

33. Murata S, Taniguchi T, Takahashi M, et al. Tissue selectivity of KMD3213 an $\alpha_{1}$-adrenoceptor antagonist, in human prostate and vasculature. J Urol. 2000;164:578-583.

34. Yamada S, Kato Y, Okura T, Kagawa Y, Kawabe K. Prediction of $\alpha_{1}$-adrenoceptor occupancy in the human prostate from plasma concentrations of silodosin, tamsulosin and terazosin to treat urinary obstruction in benign prostatic hyperplasia. Biol Pharm Bull. 2007;30(7):1237-1241.

35. Kawabe K, Yoshida M, Arakawa S, Takeuchi H. Long-term evaluation of silodosin, a new alpha1A-adrenoceptor selective antagonist for the treatment of benign prostatic hyperplasia: phase III long-term study. Jpn J Urol Surg. 2006;19:153-164.

36. Takao T, Tsujimura A, Kiuchi H, et al. Early efficacy of silodosin in patients with lower urinary tract symptoms suggestive of benign prostatic hyperplasia. Int J Urol. 2008;15(11):992-996.

37. Ogawa T, Uemura H, Sano F, et al. Multi-center trial on the early effects of silodosin on lower urinary tract symptoms associated with benign proststic hyperplasia. Acta Jpn Urol. 2008;54:757-764.

38. Yamanishi T, Mizuno T, Watanabe M, Kamai T, Yoshida KI. Urodynamic effects of silodosin, a new $\alpha 1 \mathrm{~A}$-adrenoceptor selective antagonist, for the treatment of benign prostatic hyperplasia. Neurourol Urodynam. 2009: In press.

39. Matsukawa Y, Hattori R, Komatsu T, et al. Early efficacy of silodosin on storage and voiding function in patients with benign prostatic hyperplasia, based on pressure-flow study. J Urol. 2009;181(Suppl 4):694.

40. Tatemichi S, Akiyama K, Kobayashi M, Yamazaki Y, Yokoyama O, Uruno T. A selective alpha1A-adrenoceptor antagonist inhibits detrusor overactivity in a rat model of benign prostatic hyperplasia. $J$ Urol. 2006;176:1236-1241.

41. Moriyama N, Kurimoto S, Horie S, et al. Detection of $\alpha_{1}$-adrenoceptor subtypes in human hypertrophied prostate by in situ hybridization. Histochem J. 1996;28:283-288.

42. Nasu K, Moriyama N, Kawabe K, et al. Quantification and distribution of $\alpha_{1}$-adrenoceptor subtype mRNAs in human prostate: comparison of benign hypertrophied tissue and nonhypertrophiedtissue. $\mathrm{Br} J$ Pharmacol. 1996;119:797-803.

43. Roehrborn CG, Schwinn DA. $\alpha 1$-Adrenergic receptors and their inhibitors in lower urinary tract symptoms and benign prostatic hyperplasia. J Urol. 2004;171:1029-1035.

44. Rudner XL, Berkowitz DE, Booth JV, et al. Subtype specific regulation of human vascular alpha(1)-adrenergic receptors by vessel bed and age. Circulation. 1999;100:2336-2343.

45. Malloy BJ, Price DT, Price RR, et al. $\alpha_{1}$-Adrenergic receptor subtypes in human detrusor. J Urol. 1998;160:937-943. 
46. Hampel C, Dolber PC, Smith MP, et al. Modulation of bladder $\alpha_{1}$-adrenergic receptor subtype expression by bladder outlet obstruction. J Urol. 2002;167:1513-1521.

47. Nomiya M, Yamaguchi O. A quantitative analysis of mRNA expression of alpha 1 and beta-adrenoceptor subtypes and their functional roles in human normal and obstructed bladders. J Urol. 2003;170:649-653.

48. Smith MS, Schambra UB, Wilson KH, et al. Alpha1-adrenergic receptors in human spinal cord: specific localized expression on mRNA encoding $\alpha 1$-adrenergic receptor subtypes at four distinct levels. Brain Res Mol Brain Res. 1999;63:254-261.

49. Sugaya K, Nishijima S, Miyazato M, Ashitomi K, Hatano T, Ogawa Y. Effects of intrathecal injection of tamsulosin and naftopidil, alpha-1A and-1D adrenergic receptor antagonists, on bladder activity in rats. Neurosci Lett. 2002;328:74-76.

50. Yoshiyama M, DeGroat WC. Role of spinal $\alpha 1$-adrenoceptor subtypes in the bladder reflex in anesthetized rats. Am J Physiol. 2001;280: R1414-R1419.

51. Nishino Y, Masue T, Miwa K. Comparison of two $\alpha 1$-adrenoceptor antagonists, naftopidil and tamsulosin hydrochloride, in the treatment of lower urinary tract symptoms with benign prostatic hyperplasia: a randomized cross over study. BJU Int. 2006;97:747-751.

52. Ikemoto I, Kiyota H, Ohishi Y. Usefuness of tamsulosin hydrochloride and naftopidil in patients with urinary disturbances caused by benign prostatic hyperplasia: a comparative, randomized, two-drug crossover study. Int J Urol. 2003;10:587-594.

53. Oh-oka H. Effect of naftopidil on nocturia after failure of tamsulosin. Urology. 2008;72(5):1051-1055.

54. Ukimura O, Kanazawa M, Fujihara A, Kamoi K, Okihara K, Miki T; Kyoto Prefectural University of Medicine Benign Prostatic Hypertrophy Research Group. Naftopidil versus tamsulosin hydrochloride for lower urinary tract symptoms associated with benign prostatic hyperplasia with special reference to the storage symptom: a prospective randomized controlled study. Int J Urol. 2008;15(12):1049-1054.

55. Momose H, Hosokawa Y, Kishino T, Ono T, Oyama N. Crossover comparison study on the therapeutic effects of tamsulosin hydrochloride and naftopidil in lower urinary tract symptoms associated with benign prostatic hyperplasia. Drugs Today. 2007;43(Suppl A):1-10.

56. Gotoh M, Kamihira O, Kinukawa T, Ono Y, Ohshima S, Origasa H; Tokai Urological Clinical Trial Group. Comparison of tamsulosin and naftopidil for efficacy and safety in the treatment of benign prostatic hyperplasia: a randomized controlled trial. BJU Int. 2005;96:581-586.
57. Kira S, Yamagishi T, Inuzuka H, et al. Siloodosin, a novel alpha $1 \mathrm{~A}$ AR-super selective antagonist, rapidly improves bothersome nocturia in patients who are resistant to tamsulosin/naftopidil [abstract]. $J$ Urol. 2009;181(4):695.

58. Pinggera GM, Mitterberger M, Pallwein L, et al. Alpha-blockers improve chronic ischaemia of the lower urinary tract in patients with lower urinary tract symptoms. BJU Int. 2007;101:319-324.

59. Saito M, Tominaga L, Nanba E, Miyagawa I. Expression of heat shock protein 70 and its $\mathrm{mRNAs}$ during ischemia-perfusion in the rat prostate. Eur J Pharmacol. 2004;487:199-203.

60. Shabsigh A, Hayek OR, Weiner D, et al. Acute increase in blood flow to the rat bladder subsequent to partial bladder outlet obstruction. Neurourol Urodyn. 2000;19:195-208.

61. Muramatsu I, Morishima S, Suzuki F, et al. Identification of alpha 1L-adrenoceptor in mice and its abolition by alpha 1A-adrenoceptor gene knockout. Br J Pharmacol. 2008;155(8):1224-1234.

62. Morishima S, Tanaka T, Yamamoto H, et al. Identification of alpha$1 \mathrm{~L}$ and alpha-1A adrenoceptors in human prostate by tissue segment binding. J Urol. 2007;177(1):377-381.

63. Hisasue S, Furuya R, Itoh N, Kobayashi K, Furuya S, Tsukamoto T. Ejaculatory disorder caused by alpha-1 adrenoceptor antagonists is not retrograde ejaculation but a loss of seminal emission. Int J Urol. 2006;13(10):1311-1316.

64. Michael MC. $\alpha 1$-adrenoceptors and ejaculatory function. $\mathrm{Br} J$ Pharmacol. 2007;152:289-290.

65. Sanbe A, Tanaka Y, Fujiwara Y, et al. Alpha1-adrenoceptors are required for normal male sexual function. Br J Pharamacol. 2007;152:332-340.

66. Schwinn D. $\alpha_{1}$-adrenergic receptor antagonists and the iris: new mechanistic insights into floppy iris syndrome. Surv Ophthalmol. 2006;51:501-512.

67. Chang DF, Campbell JR. Intraoperative floppy iris syndrome associated with tamsulosin. J Cataract Refract Surg. 2005;31:664-673.

68. Oshika T, Ohashi Y, Inamura M, et al. Incidence of intraoperative floppy iris syndrome in patients on either systemic or topical $\alpha_{1}$-adrenoceptor antagonist. Am J Ophtalmol. 2007;143:150-151.

69. Michel M, Okutsu H, Noguchi Y, et al. In vivo studies on the effects of alpha1-adrenoceptor antagonists on pupil diameter and urethral tone in rabbits. Naunyn Schmiedebergs Arch Pharmacol. 2006;372:346-353.
Open Access Journal of Urology

\section{Publish your work in this journal}

The Open Access Journal of Urology is an international, peer-reviewed, open access journal publishing original research, reports, editorials, reviews and commentaries on all aspects of adult and pediatric urology in the clinic and laboratory including the following topics: Pathology, pathophysiology of urological disease; Investigation and treatment of

\section{Dovepress}

urological disease; Pharmacology of drugs used for the treatment of urological disease. The manuscript management system is completely online and includes a very quick and fair peer-review system, which is all easy to use. Visit http://www.dovepress.com/testimonials.php to read real quotes from published authors. 